$\begin{array}{llllllllll} & \mathrm{D} & \mathrm{I} & \mathrm{T} & \mathrm{O} & \mathrm{R} & \mathrm{I} & \mathrm{A} & \mathrm{L}\end{array}$

\title{
Narrativas, docencia universitaria e investigación educativa
}

\author{
Analía Leite, ${ }^{*}$ Daniel Suárez ${ }^{* *}$
}

\begin{abstract}
Recibido: 27 de septiembre de 2020 Aceptado: 28 de septiembre de 2020 Publicado: 30 de septiembre de 2020
To cite this article: Leite, A. y Suárez, D. (2020). Narrativas, docencia e investigación educativa. Márgenes, Revista de Educación de la Universidad de Málaga, 1 (3), 2-5

DOI: https://doi.org/10.24310/mgnmar.v1i3.10242
\end{abstract}

El special issue que presentamos da cuenta de la complejidad de interpretar el mundo educativo y la experiencia pedagógica desde y mediante narrativas. Aun un rápido repaso del índice permite apreciar cómo esa complejidad se torna despliegue y diversidad, aun en esta pequeña muestra de veintiún textos y casi treinta autores y autoras. Si se profundiza la lectura de los artículos, se percibirá además cómo esa multiplicidad de abordajes, escrituras y proyecciones delimitan un enfoque o perspectiva específicos, relativamente bien delimitados, con reglas de composición y un campo de legitimidad, conversación y debate propios. Cómo, a pesar de sus diferencias y singularidades, esa diversidad de miradas y textos configura un modo particular de comprender e interrogarse sobre el mundo educativo y el acto pedagógico. Y cómo esa trama de sensibilidades e inteligencias en diálogo genera disposiciones otras, emergentes, insubordinadas, para vivir, comprometerse y relacionarse de otra manera con los sujetos que habitan y participan en ellos. Más allá de sus divergencias y puntos de fuga, todos estos esfuerzos se orientan en lo fundamental a "profundizar narrativamente" la educación (Contreras, 2016), a recrear su lenguaje teórico y político de la educación, y a generar un imaginario pedagógico de indagación más sensible a sus novedades, obviedades y opacidades.

Tal vez, la peculiaridad de la narrativa que colabora para esa convergencia sea la de presentársenos como un camino de doble vía. Una, cuya dirección nos permite interrumpir, desmontar y desmoronar ideas, categorías y relatos marcados o colonizados por determinados modelos ontoepistémico-metodológicos sobre la vida, la docencia, la formación, la investigación y las realidades educativas que heredamos y que colaboramos a hacer. Otra vía, de sentido inverso pero entramada con la anterior, que nos lleva a reconstruir, unir, hilar, tejer, conectar y revitalizar los modos en que pensamos y contamos la experiencia de habitar nuestros territorios y momentos educativos. Un sendero de ida y vuelta que nos propone una manera de hacer, pensar y decir el mundo educativo, de dialogar con sus habitantes, de comprender y recrear los sentidos y significados educativos que se ponen a jugar en la disputa por nominarlo. Este doble carácter disruptivo, deconstructivo 
y, al mismo tiempo, restitutivo, vital, torna al enfoque narrativo de la formación, la investigación y la práctica docente un territorio fértil para la exploración y la experimentación de dispositivos, estrategias e intervenciones. Tal vez por eso generó una pluralidad de vertientes, apropiaciones y reapropiaciones que dificultan cualquier consideración vicaria o exhaustiva de lo producido en este campo emergente, potente y cada vez más influyente. Como sabemos, narrar siempre supone narrar-se y a la vez abrir e imaginar mundos, crear significados insospechados, reconocer otros mundos, conversar con otros de otros mundos, conversar con sí mismo como otro (Ricoeur, 2011). Nos hace configurar en una totalidad coherente, cuestiones y sucesos dispersos de lo vivido: una trama de acontecimientos que se suceden en un "tiempo narrativo" y que permiten presentarnos como una "identidad narrativa" a través de su intriga (Ricoeur, 2006). Si se trata de un relato de experiencia educativa, la selección y la configuración narrativa de esos elementos dispersos están reguladas por criterios y valoraciones pedagógicas: el tiempo y el mundo del relato dan cuenta de nuestra interpretación pedagógica de los acontecimientos vividos. La intriga del relato se construye en torno de una experiencia que vivimos, o de la que fuimos testigos, indagamos o nos informamos, y no solo sobre nuestra vida o práctica profesional como una totalidad que se expresa evolutivamente en el tiempo. Por eso, el acto de narrar también implica un cierto distanciamiento, una cierta asincronía, un ejercicio inevitable de reflexividad y una permanente problematización de lo ya dicho, representado o escrito y de lo observado, escuchado o leído.

Narrar es la condición antropológica, transcultural y transhistórica del devenir humano (Barthes, 1996), de experimentar el tiempo y de temporalizar la experiencia de habitar el mundo humano, y de poder recrearlos mediante la escucha y la lectura (Ricoeur, 2006; Rivas, 2007). La práctica humana de narrar consiste en contar los mundos vividos o imaginados para, inmediatamente, ponerlos en búsqueda o en contacto con la escucha o la lectura y, a través de ella, con el mundo del receptor o lector. La narrativa de experiencia es siempre una narrativa de sí, y se involucra en la construcción social de la identidad personal y profesional (Contreras y Pérez de Lara, 2010). En la misma acción que supone la narración, no solo se re-conoce y se re-crea el sujeto sino también a la propia comunidad y los contextos cotidianos e históricos. Los relatos comprometen nuestra participación singular, única, en una experiencia que siempre es colectiva, comunitaria, plural, y que nos trasciende. Por eso, no pueden dejar de narrar "lo que acontece" en el mundo para contar tan solo "lo que nos sucede": lo que nos sucede siempre acontece entre coordenadas históricas, geográficas, económicas, sociales, culturales, políticas, que también son interpretadas por el narrador mediante su relato. Las acciones narradas siempre tienen lugar y tiempo en un escenario en el que confluyen dimensiones que prefiguran los acontecimientos a narrar y la enunciación narrativa misma. También delimitan una posición de sujeto de la acción (el personaje o actante que hace jugar la acción en la trama) y una posición de enunciación, de alguien que dice algo respecto de otros, o de sí mismo, que viven, o vivo, una experiencia en ciertas circunstancias espacio-temporales. Lo cierto es que la narrativa ha irrumpido en el campo educativo generando una disrupción teórica y metodológica y un giro epistemo-político radical. Los docentes, los alumnos y los diferentes actores que habitan el mundo de la educación ya no son considerados como meros "objetos" de los procesos de producción de conocimiento educativo, sobre los cuales se dirigen y actúan los dispositivos, recursos e instrumentos de indagación, sino que se reposicionan como sujetos de investigaciones orientadas por criterios dialógicos, políticas de conocimiento y estructuras de participación que los re-conocen como interlocutores, sujetos de saber, experiencia y discurso, y co-partícipes o colaboradores en los procesos de producción, circulación 
y recepción de saberes pedagógicos. Los dispositivos metodológicos centrados en la construcción de narrativas de sí, relatos de experiencia e historias de oficio se han difundido de manera ostensible en el territorio de la formación y el desarrollo profesional docente (Suárez, 2014; Márquez, Cortés, Leite y Espinosa, 2019). Cada vez más investigadores e investigadoras educativos utilizan en sus estudios recursos y técnicas de esta tradición de investigación (Souza, Serrano y Ramos, 2014). En el último decenio se han conformado una comunidad científica internacional, redes de investigadores y un corpus bibliográfico en diferentes lenguas muy consolidados e influyentes, en torno de la apropiación educativa de esta perspectiva de investigación, formación y acción. Y existe un creciente consenso acerca de que sus resultados y comprensiones han profundizado la mirada especializada sobre los significados y los sentidos que ponen a jugar los sujetos educativos mientras experimentan el mundo de la educación y narran su experiencia en él. Además de una vasta y profusa literatura especializada -y que se expresa en colecciones de libros, libros, revistas científicas y profesionales, dossiers temáticos, tesis de doctorado y maestría, informes de investigación, materiales pedagógicos-, tanto en el Norte como en el Sur y a ambos lados del Atlántico, siguen desarrollándose sociedades científicas y redes académicas de investigadores que producen acontecimientos para el intercambio de experiencias, el debate teórico y metodológico, la discusión epistemológica y la organización colectiva de la cooperación, que dan pistas sobre esta proliferación, difusión y pregnancia del enfoque.

Narrativa, biografía, experiencia, formación, investigación, docencia y pedagogía resuenan juntas en la puja por el lenguaje legítimo en educación y abren oportunidades inéditas para el debate metodológico, epistemológico y político y para la experimentación pedagógica basada en conocimientos locales y saberes de experiencia. Los frecuentes diarios de enseñanza, bitácoras de aula y crónicas escolares escritos por docentes reflexivos tienen un valor pedagógico y etnográfico cada vez más explorado por la investigación educativa. Esas narrativas resultaron ser muy significativas y densas para la reconstrucción de la vida cotidiana de la escuela, la documentación del mundo pedagógico vivido y la comprensión de las dinámicas locales de la transmisión cultural y del currículum en acción. Nos ofrecen materiales documentales ineludibles para una "hermenéutica de la acción pedagógica" y la comprensión de los procesos de constitución, reproducción y transformación del mundo escolar (Suárez, 2014). Por su parte, las historias de vida, las auto-etnografías, las autobiografías profesionales, las biografías de oficio y los memoriales de docentes, también muy difundidos últimamente en el campo pedagógico, nos permiten conocer de una manera más sensible e integral los singulares recorridos de afiliación al oficio (Bullough, 2000) y las tensiones puestas en juego en los procesos de construcción de la identidad profesional docente (Passeggi y de Sousa, 2010). Entrelazadas en sus tramas, emergen reflexiones pedagógicas y didácticas situadas en territorio, se identifican indicios de conocimientos pedagógicos locales y descripciones densas que profundizan el detalle, lo singular e irrepetible y lo significativo de la acción relatada como experiencia.

El abanico de producciones que se presentan nos llevan a: grupos de investigación, a tesis doctorales, a experiencias docentes, a reflexiones e ideas generadas de manera colectiva, a trayectorias personales y nuevos descubrimientos desde la posibilidad de volver a mirar, pensar, reconocer y componer otros textos y otras realidades. También nos llevan a distintos recorridos metodológicos que ponen en primer plano las narraciones bajo o desde formatos varios, así se parte de entrevistas, de revisión de escritos/documentos anteriores, de reconocimiento de metáforas, de autobiografías, de diálogos y encuentros donde transcurren y discurren vidas, insti- 
tuciones, grupos. Todo esto, ¿para qué?, para poner en juego la multiplicidad de significados que nos acercan al otro, a la otra, en sentido amplio y a nosotros mismos. Podemos pensar las narrativas con un valor democratizador o una dimensión democratizadora porque nos pone a todos y todas en situación, en contexto, en las tramas de las vidas singulares y colectivas. Los distintos artículos, ensayos, experiencias, investigaciones y reseñas como nuevas miradas sobre otras producciones nos revelan el valor social y político del trabajo con narrativas tanto en el ámbito de la formación, la educación como la investigación. Producciones que nos enfrentan con la posibilidad de romper límites y transitar fronteras o bordes que nos abren a una creatividad no prevista que emerge en otras formas de escritura, en el reconocimiento de otros territorios aún desde las sombras que parecen querer ocultar emociones, vivencias, conflictos y desdibujar realidades. La narrativa genera, produce, crea y transforma posibilidades de ser, hacer, creer y romper, un camino ilimitado para pensar la formación y la investigación educativa.

\section{REFERENCIAS}

Barthes, R. (1996). “Introducción al análisis estructural de los relatos”. En R. Barthes, U. Eco, A. Todorov y otros, Análisis estructural del relato (pp. 7-38). Coyoacán: México.

Bullough, R. (2000). "Convertirse en profesor: la persona y la localización social de la formación del profesorado”. En J. Biddle, T. Good e I. Goodson (Eds.). La enseñanza y los profesores I. La profesión de enseñar (pp. 99-166). Barcelona: Paidós.

Contreras, J. y Pérez de Lara, N. (2010). Investigar la experiencia educativa. Madrid: Morata.

Contreras, J. (2015). “Profundizar narrativamente la educación”. En E.C. de Souza (org.), (Auto)biografías e documentacao narrativa. Redes de pesquisa e formacao (pp. 37-62). Edufba, Salvador.

Contreras, J. (2016). Profundizar narrativamente la enseñanza. En I. Braganca, I., M. E: Abrahao y M. Ferreira, M. (Orgs.). Perpectivas epistémico-metodológicas da pesquisa (auto)biográfica. Sao Paulo: Editora CRV.

De Souza, E. C., Serrano Castañeda, J. A. y Ramos Morales, J. M. (2014). Autobiografía y educación: tradiciones, diálogos y metodologías. Sección Temática. Revista Mexicana de investigación Educativa (RMIE), 19(62), 683-694.

Márquez García, M.J., Cortés Gonzalez, P., Leite Mendez A. y Espinosa Torres, I. (Coords). (2019). Narrativas de vida y educación. Diálogos para el cambio social. Barcelona: Octaedro.

Passeggi, M. C. y de Souza, E. C. (Org.) (2010). Memoria docente, investigación y formación. Buenos Aires: CLACSO y Facultad de Filosofía y Letras-UBA.

Ricoeur, P. (2011). Sí mismo como otro. México: Siglo XXI.

Ricoeur, P. (2006). Tiempo y narración. México: Siglo XXI

Suárez, D. H. (2014). Espacio (auto) biográfico, investigación educativa y formación docente en Argentina. Un mapa imperfecto de un territorio en expansión. Revista Mexicana de Investigación Educativa, XIX (62), 763-786.

Rivas, J. I. (2007). "Vida, experiencia y educación: la biografía como estrategia de conocimiento”. En I. Sverdlick (comp.). La investigación educativa. Una herramienta de conocimiento y de acción (pp. 111145). Buenos Aires: Ediciones Novedades Educativas. 